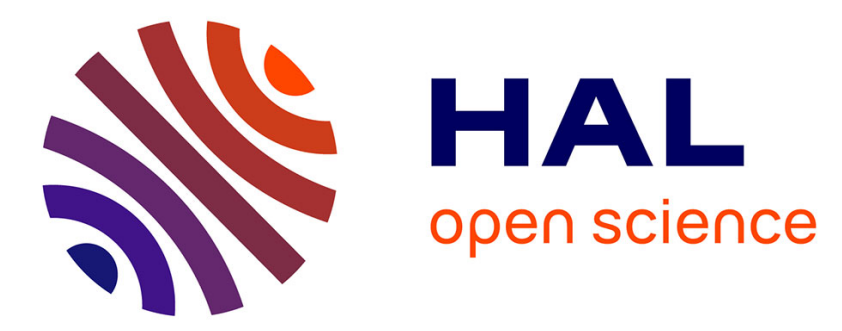

\title{
[Au12(SR)6]2-, As Smaller 8-Electron Gold Nanocluster Retaining an SP3-Core. Evaluation of Bonding and Optical Properties from Relativistic DFT Calculations
}

\author{
Alvaro Munoz-Castro, Jean-Yves Saillard
}

\section{> To cite this version:}

Alvaro Munoz-Castro, Jean-Yves Saillard. [Au12(SR)6]2-, As Smaller 8-Electron Gold Nanocluster Retaining an SP3-Core. Evaluation of Bonding and Optical Properties from Relativistic DFT Calculations. ChemPhysChem, 2018, 19 (15), pp.1846-1851. 10.1002/cphc.201800088 . hal-01812456

HAL Id: hal-01812456

https://hal-univ-rennes1.archives-ouvertes.fr/hal-01812456

Submitted on 3 Jul 2018

HAL is a multi-disciplinary open access archive for the deposit and dissemination of scientific research documents, whether they are published or not. The documents may come from teaching and research institutions in France or abroad, or from public or private research centers.
L'archive ouverte pluridisciplinaire HAL, est destinée au dépôt et à la diffusion de documents scientifiques de niveau recherche, publiés ou non, émanant des établissements d'enseignement et de recherche français ou étrangers, des laboratoires publics ou privés. 


\title{
$\left[\mathrm{Au}_{12}(\mathrm{SR})_{6}\right]^{2-}$, As Smaller 8-electron Gold Nanocluster Retaining an $\mathrm{SP}^{3}$-core. Evaluation of Bonding and Optical Properties from Relativistic DFT Calculations
}

\author{
Alvaro Muñoz-Castro ${ }^{\mathrm{a}^{*}}$ and Jean-Yves Saillard ${ }^{\mathrm{b}^{*}}$ \\ ${ }^{a}$ Grupo de Química Inorgánica y Materiales Moleculares, Facultad de Ingenieria, \\ Universidad Autonoma de Chile, El Llano Subercaseaux 2801, Santiago, Chile. \\ ${ }^{b}$ Univ Rennes, CNRS, ISCR-UMR 6226, F-35000 Rennes, France.
}

\begin{abstract}
Exploring the versatility of atomically precise clusters is a relevant issue in the design of functional nanostructures. Superatomic clusters offer an ideal framework to gain further understanding of the different distinctive size-dependent physical and chemical properties. Here, we propose $\left[\mathrm{Au}_{12}(\mathrm{SR})_{6}\right]^{2-}$ as a minimal 8-electron superatom related to the prototypical $\left[\mathrm{Au}_{25}(\mathrm{SR})_{18}\right]^{-}$cluster, depicting half of its core-mass $(2.3 \mathrm{kDa}$ vs 5.0 $\mathrm{kDa})$.

The $\left[\mathrm{Au}_{12}(\mathrm{SMe})_{6}\right]^{2-}$ cluster fulfills a $1 \mathrm{~S}^{2} 1 \mathrm{P}^{6}$ electronic configuration, with a distorted tetrahedral $\mathrm{Au}_{8}$ core further viewed as an $\mathrm{SP}^{3}$-hybridized superatom. The distinctive optical properties show a blue-shift for the first relevant $1 \mathrm{P} \rightarrow 1 \mathrm{D}$ transition, in comparison to $\left[\mathrm{Au}_{25}(\mathrm{SR})_{18}\right]^{-}$. In addition, chiroptical activity is observed, denoting intrinsic core chirality. We expect that our results can shed light into the variation of the molecular properties according to the size-dependent properties, and serve as guidelines for further experimental exploration of minimal or ultrasmall nanoclusters.

\footnotetext{
*alvaro.munoz@uautonoma.cl

* jean-yves.saillard@univ-rennes1.fr
} 


\section{Introduction}

gold nanostructures have attracted great interest as fundamental building blocks in nanoscience, driven by the fact that these aggregates with variable sizes, can serve as building blocks in functional nanomaterials, ${ }^{[1-12]}$ with applications in catalysis, sensing biomedicine,$^{[9,10,13-18]}$ as well as nanoelectronic devices. ${ }^{[19,20]}$ Since the last decade, efforts on the understanding of stable gold clusters, have been paid to the rationalization of their structural and electronic properties, ${ }^{[21-27]}$ where ligand-protected (LP) gold clusters has led to a plethora of new structures, ${ }^{[22,27]}$ reaching atomically precise sizes with particular stability against degradation. ${ }^{[5,28-32]}$ Small nanosized gold clusters $(<2$ $\mathrm{nm}$ ) exhibit a molecule-like behavior featuring a frontier level bandgap, ${ }^{[21,33-37]}$ where well-defined structures are relevant to study the evolution from small aggregates to nanocrystals $(>2 \mathrm{~nm})$, as has been observed for example for the tetrahedral $\left[\left({ }^{t} \mathrm{Bu}\right)_{3} \mathrm{PAu}\right]_{4}{ }^{2+} \cdot{ }^{[38,39]}$ Recently, an ultrasmall gold nanoclusters protected by diphosphine ligands has been reported by Sun. ${ }^{[40]}$ Such nanoparticles exhibit properties that differ from those of the bulk and molecular states and exhibit a strong size-dependent behavior. Thus, it is necessary for practical applications to know and understand how their inherent properties vary according to their size.

The $\left[\mathrm{Au}_{25}(\mathrm{SR})_{18}\right]^{-}$anionic cluster, is one of the most prominent member of LP gold clusters which can be viewed as a centered icosahedral $\mathrm{Au}_{13}$ core surrounded by a protecting layer composed by six dimeric $\mathrm{Au}_{3}(\mathrm{SR})_{2}$ staple units. ${ }^{[5]}$ The inner core, formally $\left[\mathrm{Au}_{13}\right]^{5+}$, possesses 8 cluster electrons (ce), according to the electron counting rules given by Häkkinen and coworkers, ${ }^{[6,21]}$ fulfilling a $1 \mathrm{~S}^{2} 1 \mathrm{P}^{6}$ closed-shell electronic configuration in analogy to noble gas atoms, ${ }^{[41]}$ and thus coined as a superatom. ${ }^{[7,12,32,42,43]}$

It is noteworthy that the "magic" 8-ce count is also favored for a smaller pseudospherical structure, namely the tetracapped tetrahedron. $\mathrm{Cu}_{4} \mathrm{Zn}_{4}\left(\mathrm{CN}^{t} \mathrm{Bu}\right)_{4} \mathrm{Cp} *$ is a typical example of such an octanuclear LP closed-shell species. ${ }^{[44]}$ In the case of gold, the 8-ce count is achieved for a neutral tetracapped tetrahedron and indeed this architecture is a closed-shell energy minimum for $\mathrm{Au}_{8}{ }^{[45]}$ However, the $\mathrm{Au}_{8}$ structure of lowest energy is known to be planar. ${ }^{[21]}$ Nevertheless, it could be possible to stabilize a tetracapped tetrahedral $\mathrm{Au}_{8}$ core by decorating it with a protecting shell similar to that existing in $\left[\mathrm{Au}_{25}(\mathrm{SR})_{18}\right]^{-}$. Herein we explore the possibility of existence of an 8-ce LP cluster exhibiting a tricapped tetrahedral core, analogous to $\left[\mathrm{Au}_{25}(\mathrm{SR})_{18}\right]^{-}$, but of lower 
nuclerarity, namely $\left[\mathrm{Au}_{12}(\mathrm{SR})_{6}\right]^{2-}$, which can be a potential addition to libraries of ultrasmall gold nanoclusters. ${ }^{[40]} \mathrm{We}$ analyze both its structure and electronic structure, besides of its optical properties, in order to provide useful information of size-dependent behavior for further explorative synthesis and characterization. ${ }^{[27]}$

\section{Computational Details}

Relativistic density functional theory (DFT) calculations ${ }^{[46]}$ were carried out by using the ADF code ${ }^{[47]}$, incorporating scalar (SR) corrections via the one and two-component ZORA Hamiltonian $^{[48]}$, respectively. We employed the triple- $\xi$ Slater basis set, plus two polarization functions (STO-TZ2P) for valence electrons, within the generalized gradient approximation (GGA) according to the Perdew-Burke-Ernzerhof (PBE) exchange-correlation functional ${ }^{[49,50]}$ because of its improved performance on longrange interactions and relatively low computational cost employed in similar clusters, allowing a direct comparisons with other computational studies of gold nanoclusters ${ }^{[12,26,51-53]}$. London dispersion corrections were included through the pairwise Grimme approach (Grimme-D3). ${ }^{[54,55]}$ The frozen core approximation was applied to the $\left[1 \mathrm{~s}^{2}-4 \mathrm{f}^{14}\right]$ shells for $\mathrm{Au},\left[1 \mathrm{~s}_{2}-2 \mathrm{p}^{6}\right]$ for $\mathrm{S}$, and $\left[1 \mathrm{~s}^{2}\right]$ for $\mathrm{C}$, leaving the remaining electrons to be treated variationally. Geometry optimizations were performed without any symmetry restrain, via the analytical energy gradient method implemented by Versluis and Ziegler. ${ }^{[56]}$ The nature of each optimized stationary point on the potential energy surface (PES) was determined by examining the second derivative of the energy with respect to the coordinates (Hessian). ${ }^{[57,58]}$ An energy convergence criterion of $10^{-4}$ Hartree, gradient convergence criteria of $10^{-3}$ Hartree/A and radial convergence criteria of $10^{-2} \AA$ were employed for the evaluation of the relaxed structures. Solvent and counterion effects were considered by using the conductor-like screening model ${ }^{[59,60]}$ (COSMO) with acetonitrile as solvent. Time-dependent DFT (TD-DFT) calculations were employed at the same level, but using the Perdew-Burke-Ernzerhof (PBE) exchange-correlation functional allowing further comparison with other computational studies of superatomic nanoclusters. ${ }^{[52,53,61-63]}$ 


\section{Results and Discussion}

The relaxed structure of $\left[\mathrm{Au}_{12}(\mathrm{SR})_{6}\right]^{2-}$, with $\mathrm{R}=\mathrm{Me}(\mathbf{1})$, is given in Figure 1 . It can be depicted as a quasi tetrahedral $\mathrm{Au}_{8}$ core protected by two $\mathrm{Au}_{2}(\mathrm{SR})_{3}$ motifs giving a $\left[\mathrm{Au}_{8} @\left(\mathrm{Au}_{2}(\mathrm{SR})_{3}\right)_{2}\right]^{2-}$ architecture. With a $D_{2 d}$ pseudo-symmetry, the $\mathrm{Au}_{8}$ core deviates from the ideal $T_{d}$ symmetry of a tetracapped tetrahedron, owing to the ligand shell distribution. This generates an overall $C_{2}$ (chiral) symmetry for $\mathbf{1}$, with a $C_{2}$ passing between the two $\mathrm{Au}_{2}(\mathrm{SR})_{3}$ motifs, which is related to $2-c e\left[\mathrm{Au}_{12}(\mathrm{SR})_{9}\right]^{+}{ }^{[37]}$ Averaged $\mathrm{Au}-\mathrm{Au}$ bond lengths are $2.805 \AA$ within the inner $\mathrm{Au}_{8}$ core and $2.851 \AA$ between the core and the protecting layer. This structure is favored over $\left[\mathrm{Au}_{9} @\left(\mathrm{Au}(\mathrm{SR})_{2}\right)_{3}\right]^{2-}$ by about $76.9 \mathrm{kcal} \cdot \mathrm{mol}^{-1}$ (supporting information). The Au-S distance for $\mathbf{1}$ amounts to $2.479 \AA$ A. A structural comparison with the isoelectronic superatom $\left[\mathrm{Au}_{25}(\mathrm{SR})_{18}\right]^{-}$reveals similar Au-Au separations (Table 1) where the $\mathrm{Au}$ (core)-Au(outer shell) distances are shorter in 1. Thus, both 8-ce superatoms depict related structural features, despite of the different inner core architectures (Figure 1). Further possible dimerization and decomposition were evaluated through the energy difference between reactants and products in the respective, $2 \mathrm{x}\left[\mathrm{Au}_{12}(\mathrm{SMe})_{6}\right]^{2-} \rightarrow\left[\mathrm{Au}_{24}(\mathrm{SMe})_{12}\right]^{4-}$ and $\left[\mathrm{Au}_{12}(\mathrm{SMe})_{6}\right]^{2-} \rightarrow$ $2 \mathrm{x}\left[\mathrm{Au}_{6}(\mathrm{SMe})_{3}\right]^{-}$processess. The resulting energy difference suggest that both dimerization and decomposition are disfavored in relation to $\mathbf{1}$, by 42.8 and 172.6 $\mathrm{kcal} \cdot \mathrm{mol}^{-1}$ (supporting information).

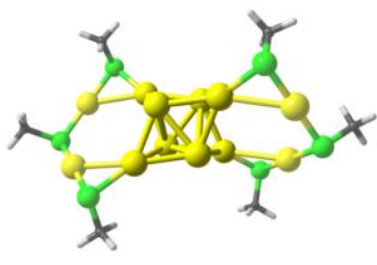

$\left[\mathrm{Au}_{12}(\mathrm{SMe})_{6}\right]^{2-}$

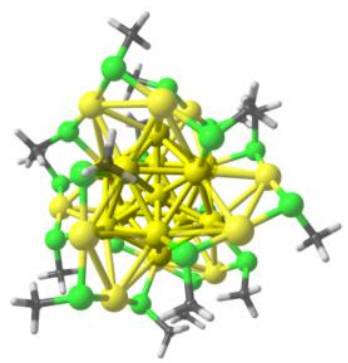

$\left[\mathrm{Au}_{25}(\mathrm{SMe})_{18}\right]^{-}$

Figure 1. The structures for $\left[\mathrm{Au}_{12}(\mathrm{SMe})_{6}\right]^{2-}$ and $\left[\mathrm{Au}_{25}(\mathrm{SMe})_{18}\right]^{-}$.

The charge distribution in $\left[\mathrm{Au}_{12}(\mathrm{SMe})_{6}\right]^{2-}$ and $\left[\mathrm{Au}_{25}(\mathrm{SMe})_{18}\right]^{-}$, obtained by using the Hirshfeld charge analysis method, ${ }^{[64,65]}$ is employed to estimate the charge at the ligand (including gold staple atoms) protecting shell, in order to evaluate the effect of the different inner cluster cores. For the former, the ligand shell exhibits a charge of -1.10 a.u, which is similar to the $\left[\mathrm{Au}_{25}(\mathrm{SMe})_{18}\right]^{-}$case, with a value of -1.22 a.u. This indicates that in both cases the negative charge is mostly distributed in the staple motif layer. 
Thus, the new 8-ce thiolate-protected cluster exhibits an overall valence electron distribution which closely resembles its experimentally known 8-ce isoelectronic counterpart. In addition, three types of different gold atoms were found in $\left[\mathrm{Au}_{12}(\mathrm{SMe})_{6}\right]^{2-}$ carrying an increasing negative charge in the order $\mathrm{Au}($ stapple $)<$ $\mathrm{Au}$ (capping) < $\mathrm{Au}$ (central tetrahedron), denoting that the central tetrahedron is able to retrain more charge in comparison to the $\left[\mathrm{Au}_{25}(\mathrm{SMe})_{18}\right]^{-}$cluster, with similar three types of gold atoms $\mathrm{Au}$ (staples) < $\mathrm{Au}(\mathrm{ico})<\mathrm{Au}($ center $)$.

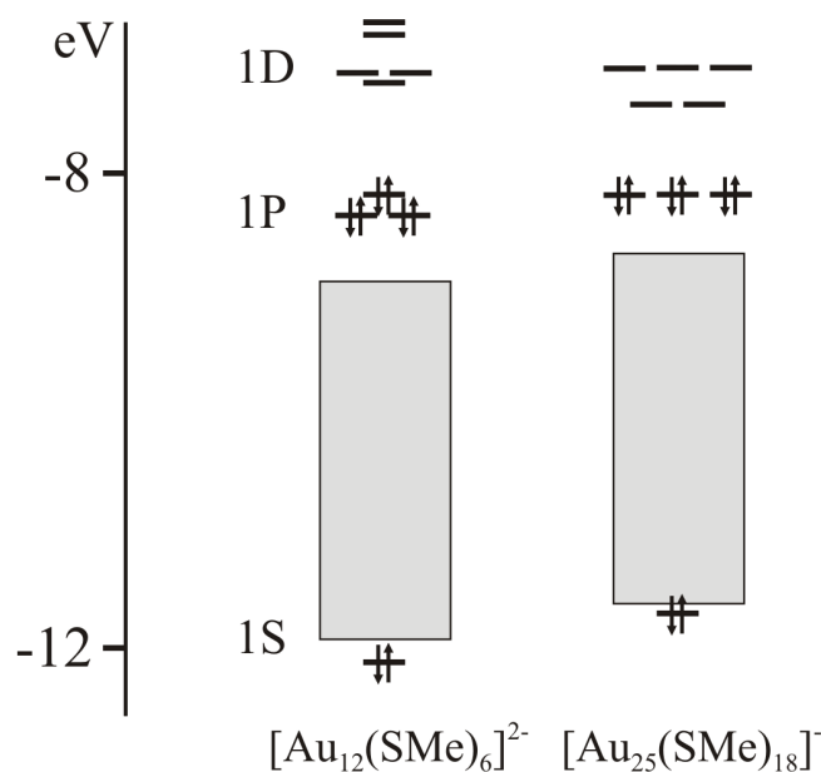

Figure 2. Kohn-Sham orbital diagrams of $\left[\mathrm{Au}_{12}(\mathrm{SMe})_{6}\right]^{2-}$ and $\left[\mathrm{Au}_{25}(\mathrm{SMe})_{18}\right]^{-}$, denoting their $1 \mathrm{~S}^{2} 1 \mathrm{P}^{6} 1 \mathrm{D}^{0}$ superatomic configuration. Grey boxes depict the " $5 \mathrm{~d}-\mathrm{Au}$ block".

The electronic structure for $\left[\mathrm{Au}_{12}(\mathrm{SMe})_{6}\right]^{2-}$ and $\left[\mathrm{Au}_{25}(\mathrm{SMe})_{18}\right]^{-}$are depicted in Figure 2. The 8-ce's are distributed on $\mathrm{S}$ and $\mathrm{P}$ superatomic shells, whereas the $1 \mathrm{D}$ shell remains unoccupied. ${ }^{[21,66,67]}$ The corresponding orbitals are plotted in Figure 3. The HOMOLUMO separation in $\mathbf{1}(1.50 \mathrm{eV})$ is larger than in $\left[\mathrm{Au}_{25}(\mathrm{SMe})_{18}\right]^{-}(1.20 \mathrm{eV})$, suggesting substantial stability. Due to the low $C_{2}$ symmetry of $\mathbf{1}$, the $1 \mathrm{P}$ and $1 \mathrm{D}$ shells are more split than in the more spherical $\left[\mathrm{Au}_{25}(\mathrm{SMe})_{18}\right]^{-}$. In particular, the $1 \mathrm{D}$ shell splits in a three below two patterns. Nevertheless, the two below one splitting of the 1P shell $(0.23$ $\mathrm{eV})$ remains small in comparison with a spherical structure. It is much smaller than in the oblate 6-ce $\left[\mathrm{PdAu}_{8}\left(\mathrm{PPh}_{3}\right)_{8}\right]^{2+}$ superatom in which the $1 \mathrm{P}$ splitting is found to be of $1.66 \mathrm{eV}$ by voltammetry ${ }^{[68]}$ and $1.87 \mathrm{eV}$ by our DFT calculations. In the case of $\left[\mathrm{Au}_{12}(\mathrm{SMe})_{6}\right]^{2-}$, the calculated $1 \mathrm{P}$ splitting lies in the $0.3 \mathrm{eV}$ range of the more spherical 
6-ce superatoms $\left[\mathrm{M} @ \mathrm{Au}_{24}(\mathrm{SR})_{18}\right] \quad(\mathrm{M}=\mathrm{Pd}, \mathrm{Pt}) .{ }^{[68-70]}$ The later species exhibit an interesting 6-ce↔8-ce interconversion upon cluster charge change (from 0 to -2$)^{[68-70]}$ This suggests that $\mathbf{1}$ can also exhibit a valence electron count variation between 8$c e \leftrightarrow 6-c e$, where optimized structures are given in Supporting Information. The 6-ce $\left[\mathrm{Au}_{12}(\mathrm{SMe})_{6}\right]^{0,}$ exhibits a $1 \mathrm{~S}^{2} 1 \mathrm{P}^{4}$ superatomic electronic configuration, similar to $\left[\mathrm{M} @ \mathrm{Au}_{24}(\mathrm{SR})_{18}\right](\mathrm{M}=\mathrm{Pd}, \mathrm{Pt}) .{ }^{[68-70]}$

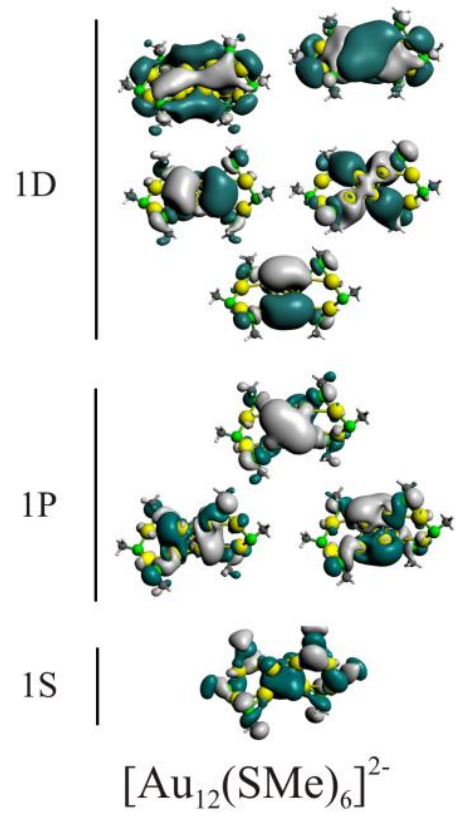

Figure 3. Isosurfaces of relevant superatomic orbitals of $\left[\mathrm{Au}_{12}(\mathrm{SMe})_{6}\right]^{2-}$ (isovalue at \pm 0.01 a.u).

In Figure 3, isosurface of superatomic shells are given for $\left[\mathrm{Au}_{12}(\mathrm{SMe})_{6}\right]^{2-}$ supporting the $1 \mathrm{~S}^{2} 1 \mathrm{P}^{6}$ electronic configuration. Thus, the proposed cluster $\mathbf{1}$ exhibits a similar electronic structure to the experimentally known $8-c e\left[\mathrm{Au}_{25}(\mathrm{SMe})_{18}\right]^{-}$superatoms and can be viewed as its smallest analog in size, with a core mass of a half. In addition, 1 appears as the next magic electron count in relation to the tetrahedral 2-ce $\left[\left({ }^{t} \mathrm{Bu}\right)_{3} \mathrm{PAu}\right]_{4}{ }^{2+}$ obtained by Schmidbaur and coworkers, and theoretically described by Pyykkö and Runeberg. ${ }^{[38,39]}$ In $\mathbf{1}$, the contribution of London dispersion corrections amounts to $5 \%$ of the cohesion energy denoting a more covalent character in the current 8-ce structure, in comparison to the half-covalent/half-metallophilic discussed for $\left[\left({ }^{t} \mathrm{Bu}\right)_{3} \mathrm{PAu}\right]_{4}{ }^{2+} \cdot[39]$

Moreover, the quasi-tetrahedral structure of the $\mathrm{Au}_{8}$ core implies that the superatomic atomic orbitals are able to hybridize during the formation of the overall structure 
analogous to a $s p^{3}$-hybridized element as central structural component. The formation of hybridized metallic cores has been described by combining $1 \mathrm{~S}$ and $1 \mathrm{P}$ shells leading to a set of hybrid orbitals. ${ }^{[71]}$ Such approach points out that concepts from VSEPR theory ${ }^{[72,73]}$ can be employed within the superatom approach to rationalize molecular shape and bonding in non spherical clusters metal clusters. In this sense, localized molecular orbitals (LMOs) were obtained using the Boys-Foster localization scheme ${ }^{\text {[74] }}$ as implemented in the ADF code, which can be related to Lewis-like bonds, including two-center two-electron (2c-2e) and multicenter bonds (nc-2e). The computed LMO's of 1 consist of a set of four equivalent orbitals (Figure 4) resulting from the combination of the $1 \mathrm{~S}$ and $1 \mathrm{P}$ orbitals (related to atomic $\mathrm{sp}^{3}$-hybrids) distributing the 8 -ce in four localized $8 \mathrm{c}-2 \mathrm{e}$ orbital involving the $\mathrm{Au}_{8}$ core. They are oriented in a quasi tetrahedral disposition denoting the hybridized $\mathrm{SP}^{3}-\mathrm{Au}_{8}$ core in the $\left[\mathrm{Au}_{12}(\mathrm{SMe})_{6}\right]^{2-}$ cluster, which can be viewed as a superatomic analogue of classical molecules such as $\mathrm{CH}_{4} \cdot{ }^{[71,75]}$

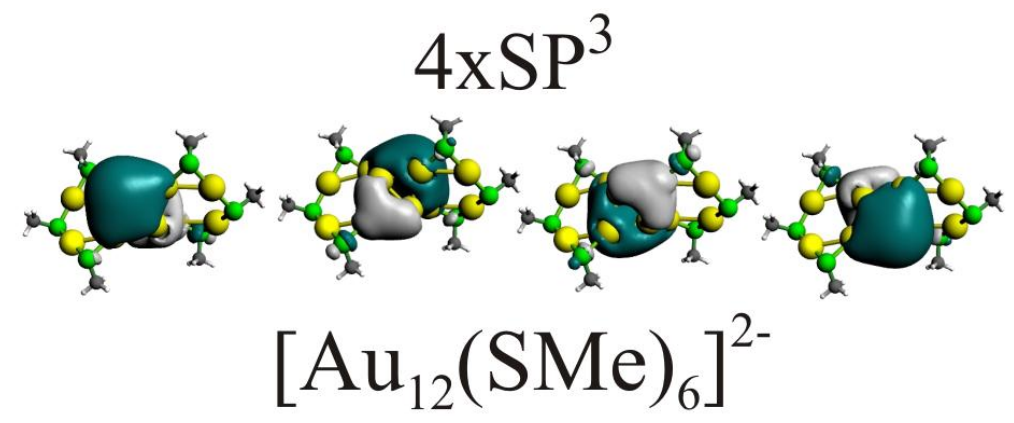

Figure 4. Isosurfaces for localized molecular orbitals of $\mathbf{1}$, denoting a set of four $\mathrm{SP}^{3}$ superatomic hybrid orbitals (isovalue at $\pm 0.01 \mathrm{a}$.u).

Moreover, $\mathbf{1}$ can be viewed as another addition to the examples of clusters based on $\mathrm{Au}_{4}$ networks, ${ }^{[38,76-79]}$ with four $\mathrm{Au}_{4}$ motifs fused together. Hence, additionally to the $\mathrm{SP}^{3}-\mathrm{Au}_{8}$ view, $\mathbf{1}$ can also be considered as a network of four $2 \mathrm{e}-\mathrm{Au}_{4}$ fused motifs contributing to the libraries of predicted $\mathrm{Au}_{4}(\mathrm{AuL}) \mathrm{n}$ nanoclusters by $\mathrm{Cheng}^{[80]}$ and Jang. ${ }^{[77]}$

The optical properties of gold nanoclusters in the low-energy region, provide useful fingerprints to assist further experimental characterization. ${ }^{[27]}$ In this sense, the optical absorption spectra up to $3.0 \mathrm{eV}$ was simulated and compared to the prototypical 8-ce $\left[\mathrm{Au}_{25}(\mathrm{SMe})_{18}\right]^{-}$cluster (Figure 5). As previously shown experimentally, ${ }^{[27,61,81,82]}$ $\left[\mathrm{Au}_{25}(\mathrm{SMe})_{18}\right]^{-}$exhibits a first low-energy electronic $\mathrm{HOMO} \rightarrow$ LUMO transition, 
ascribed to a $1 \mathrm{P} \rightarrow 1 \mathrm{D}$ transition. The corresponding peak is found at $1.41 \mathrm{eV}$, in agreement with recent theoretical analysis. ${ }^{[53]}$ The second peak observed at 2.19 depicts a combined $1 \mathrm{P} \rightarrow 1 \mathrm{D}$ and " $5 d-\mathrm{Au}$ " block $\rightarrow 1 \mathrm{D}$ transition, and a third peak at $2.49 \mathrm{eV}$ is attributed to a main " $5 d$-Au" block $\rightarrow 1 \mathrm{D}$ character.

The simulated UV-vis absorption spectrum of $\mathbf{1}$, obtained from TD-DFT calculations, is shown in Figure 6. It exhibits two main peaks, one featuring a $1 \mathrm{P} \rightarrow 1 \mathrm{D}$ transition at $1.79 \mathrm{eV}$, and the other one corresponding to a mixed band of $1 \mathrm{P} \rightarrow 1 \mathrm{D}$ and " $5 d-\mathrm{Au}$ " block $\rightarrow 1 \mathrm{D}$ character at $2.33 \mathrm{eV}$. These results illustrate the similar optical behavior in both clusters, suggesting that related properties can be preserved in the smaller isoelectronic 8-ce counterpart. Interestingly, the first $1 \mathrm{P} \rightarrow 1 \mathrm{D}$ transition is blue-shifted in 1, owing to its larger HOMO-LUMO gap, denoting a size-dependent property.

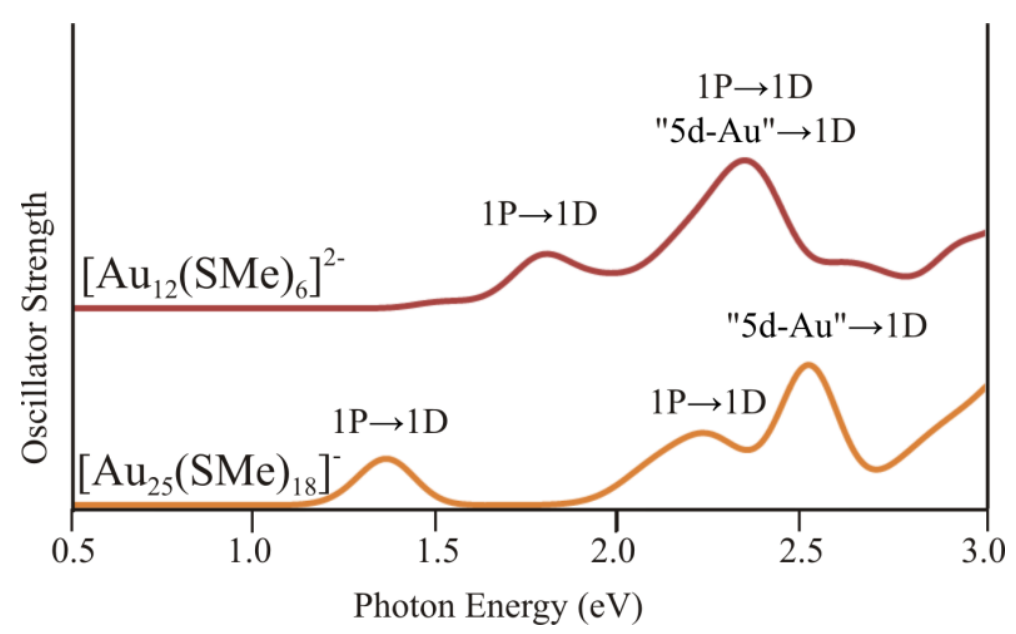

Figure 6. Simulated optical absorption spectrum for $\left[\mathrm{Au}_{12}(\mathrm{SMe})_{6}\right]^{2-}$ and $\left[\mathrm{Au}_{25}(\mathrm{SMe})_{18}\right]^{-}$.

Lastly, it is noteworthy that the existence of a chirality $C_{2}$ axis in the overall 1 cluster provides the possibility to generate intrinsic chiroptical properties ${ }^{[83-85]}$ for the two enantiomers such a structure. This prompted us to evaluate the shape and strenght of the circular dichroism (CD) spectra for the left-handed enantiomer, which can be compared to the intrinsically and strongly chiral $\left[\mathrm{Au}_{38}(\mathrm{SMe})_{24}\right]$ cluster. ${ }^{[86-88]}$ The calculated $\mathrm{CD}$ spectra (Figure 7) reveals the optical activity of $\mathbf{1}$, owing to the chiral disposition of the staple motifs over the $\mathrm{Au}_{8}$ core (see above). Both right- and left-handed enantiomers and their $\mathrm{CD}$ spectrum are given on supporting information. The obtained rotatory strenght for $\left[\mathrm{Au}_{12}(\mathrm{SMe})_{6}\right]^{2-}$ exhibits a chiral pattern showing peaks between $\sim 100$ and $7510^{-40} \mathrm{esu}^{2} \mathrm{~cm}^{2}$, which shows a weaker chiroptical strenght in comparison to the respective $\left[\mathrm{Au}_{38}(\mathrm{SMe})_{24}\right]$ cluster, with signals between 350 and $-42210^{-40} \mathrm{esu}^{2} \mathrm{~cm}^{2}$, in 
the calculated low-energy range. Most of the pattern is given by the second relevant peak found in the optical absorption spectra (see above).

These results indicate that $\mathbf{1}$ bears an intrinsic core chirality, which contrast to the achiral $\left[\mathrm{Au}_{25}(\mathrm{SMe})_{18}\right]^{-}$cluster. However, the evaluated optical activity remains small in comparison to $\left[\mathrm{Au}_{38}(\mathrm{SMe})_{24}\right]$. This indicates, that $\mathbf{1}$ can be a useful low-nuclearity chiral nanocluster, for chiral sensing or catalysis among other applications, ${ }^{[89-91]}$ which can be employed as a seed for the formation of chiral assemblies.

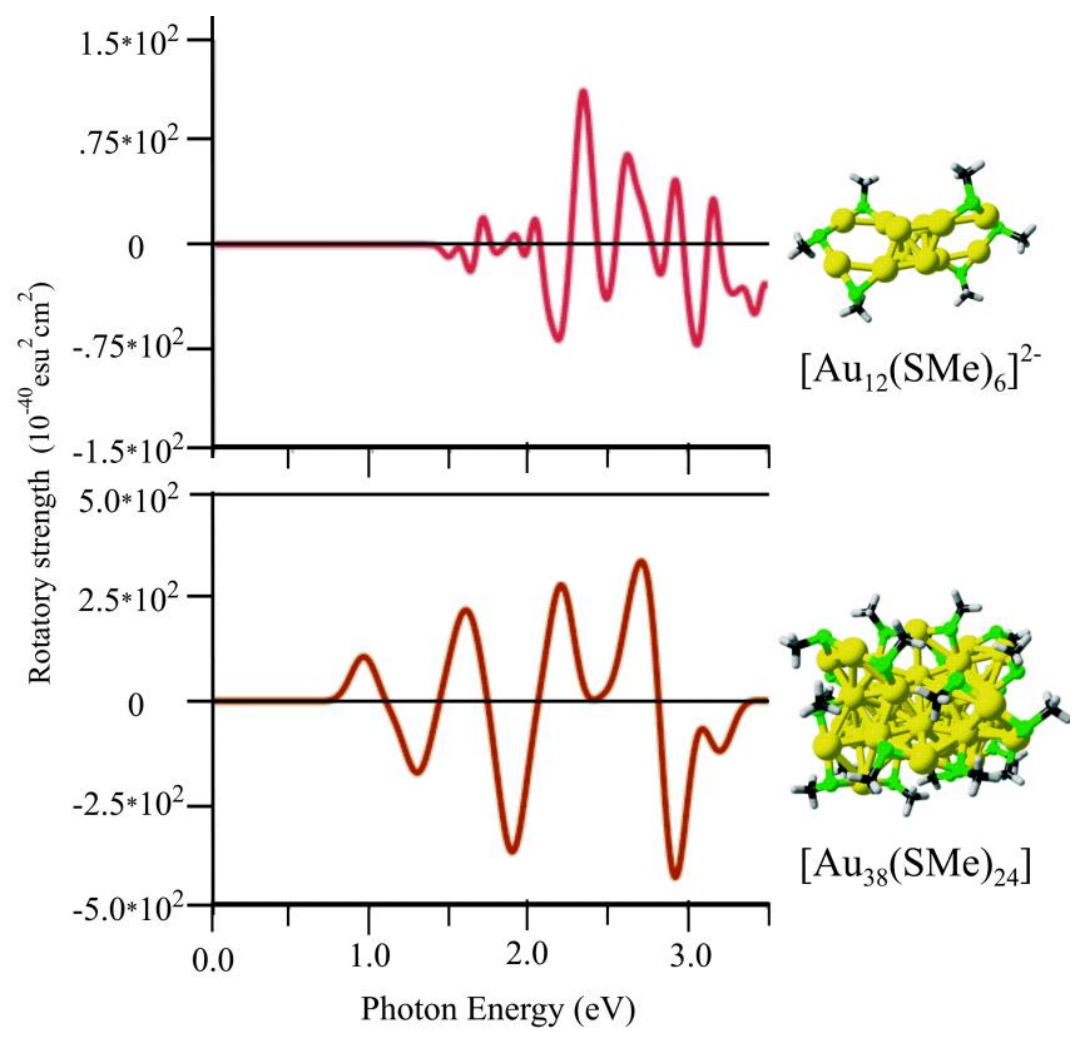

Figure 7. Calculated circular dichroism spectrum for left-handed $\left[\mathrm{Au}_{12}(\mathrm{SMe})_{6}\right]^{2-}($ above $)$ and $\left[\mathrm{Au}_{38}(\mathrm{SMe})_{24}\right]$ (below). Note the change in scale for rotator strength. 


\section{Conclusions}

In summary, here we propose the existence of a stable minimal isoelectronic counterparts to the prototypical $\left[\mathrm{Au}_{25}(\mathrm{SR})_{18}\right]^{-}$cluster, in order to further explore the sizeproperty relationship in nanoclusters. The proposed $\left[\mathrm{Au}_{12}(\mathrm{SMe})_{6}\right]^{2-}$ cluster $\mathbf{1}$, exhibits a core mass of $2.3 \mathrm{kDa}$, half of that of its $\mathrm{Au}_{25}$ counterpart $(5.0 \mathrm{kDa})$. The 8-ce count fulfills the closed-shell $1 \mathrm{~S}^{2} 1 \mathrm{P}^{6}$ electronic configuration according to the superatom approach. 1 can be further viewed as an $\mathrm{SP}^{3}$-hybridized superatom. The optical properties reveal a characteristic pattern, showing a blue-shift for the first relevant $1 \mathrm{P} \rightarrow 1 \mathrm{D}$ transition, in comparison to $\left[\mathrm{Au}_{25}(\mathrm{SR})_{18}\right]^{-}$. The resulting ligand shell distribution protecting the $\mathrm{Au}_{8}$, infers intrinsic chiroptical properties. The circular dichroism spectra for the left-handed enantiomer indicates intrinsic core chirality, which is sizable but lower than the rotator strength observed for the strongly chiral $\left[\mathrm{Au}_{38}(\mathrm{SR})_{24}\right]$ cluster. We expect that our results will serve as guidelines for further experimental exploration of minimal or ultrasmall nanoclusters.

\section{Acknowledgments}

The authors thank the financial support from FONDECYT 1180683. This research has been performed as part of the Chilean-French International Associated Laboratory for "Multifunctional Molecules and Materials" (LIA-CNRS N¹027).

\section{Supporting information available.}

Schematic structure representation in the shift between $\left[\mathrm{Au}_{12}(\mathrm{SMe})_{6}\right]^{2-}$ and $\left[\mathrm{Au}_{12}(\mathrm{SMe})_{6}\right]^{0}$, denoting a 8-ce $\leftrightarrow$ 6-ce interconversion. Lowest isomer found at 76.9 $\mathrm{kcal} \cdot \mathrm{mol}^{-1}$ above $\left[\mathrm{Au}_{8} @\left(\mathrm{Au}_{2}(\mathrm{SMe})_{3}\right)_{2}\right]^{2-}(\mathbf{1})$. Energy difference between reactants and products in the respective, $2 x\left[\mathrm{Au}_{12}(\mathrm{SMe})_{6}\right]^{2-} \rightarrow\left[\mathrm{Au}_{24}(\mathrm{SMe})_{12}\right]^{4-}$ and $\left[\mathrm{Au}_{12}(\mathrm{SMe})_{6}\right]^{2-} \rightarrow$ $2 \mathrm{x}\left[\mathrm{Au}_{6}(\mathrm{SMe})_{3}\right]^{-}$processess. Circular dichroism spectra for left- and right-handed $\left[\mathrm{Au}_{12}(\mathrm{SMe})_{6}\right]^{2-}$ enantiomers. 


\section{References}

[1] H. Qian, Y. Zhu, R. Jin, ACS Nano 2009, 3, 3795-3803.

[2] R. L. Whetten, J. T. Khoury, M. M. Alvarez, S. Murthy, I. Vezmar, Z. L. Wang, P. W. Stephens, C. L. Cleveland, W. D. Luedtke, U. Landman, Adv. Mater. 1996, 8, 428-433.

[3] L. A. Oro, P. Braunstein, P. R. Raithby, Metal Clusters in Chemistry, Wiley-vch Weinheim, Germany, 1999.

[4] M.-C. Daniel, D. Astruc, Chem. Rev. 2004, 104, 293-346.

[5] M. W. Heaven, A. Dass, P. S. White, K. M. Holt, R. W. Murray, J. Am. Chem. Soc. 2008, 130, 3754-3755.

[6] M. Walter, J. Akola, O. Lopez-Acevedo, P. D. Jadzinsky, G. Calero, C. J. Ackerson, R. L. Whetten, H. Gronbeck, H. Hakkinen, Proc. Natl. Acad. Sci. 2008, 105, 9157-9162.

[7] P. Jena, J. Phys. Chem. Lett. 2013, 4, 1432-1442.

[8] S. Knoppe, I. Dolamic, T. Bürgi, J. Am. Chem. Soc. 2012, 134, 13114-13120.

[9] Y. Levi-Kalisman, P. D. Jadzinsky, N. Kalisman, H. Tsunoyama, T. Tsukuda, D. A. Bushnell, R. D. Kornberg, J. Am. Chem. Soc. 2011, 133, 2976-2982.

[10] J. M. Galloway, J. P. Bramble, A. E. Rawlings, G. Burnell, S. D. Evans, S. S. Staniland, Small 2012, 8, 204-208.

[11] R. Jin, C. Zeng, M. Zhou, Y. Chen, Chem. Rev. 2016, 116, 10346-10413.

[12] J. Akola, K. A. Kacprzak, O. Lopez-Acevedo, M. Walter, H. Grönbeck, H. Häkkinen, J. Phys. Chem. C 2010, 114, 15986-15994.

[13] T. Tsukuda, H. Tsunoyama, H. Sakurai, Chem. Asian J. 2011, 6, 736-748.

[14] Y. Zhu, H. Qian, R. Jin, J. Mater. Chem. 2011, 21, 6793-6799.

[15] K. Kwak, S. S. Kumar, D. Lee, Nanoscale 2012, 4, 4240-4246.

[16] N. Sakai, T. Tatsuma, Adv. Mater. 2010, 22, 3185-3188.

[17] Z. Wu, M. Wang, J. Yang, X. Zheng, W. Cai, G. Meng, H. Qian, H. Wang, R. Jin, Small 2012, 8, 2028-2035.

[18] R. W. Murray, Chem. Rev. 2008, 108, 2688-2720.

[19] Z. Wu, R. Jin, Nano Lett. 2010, 10, 2568-2573.

[20] L. Li, H. Liu, Y. Shen, J. Zhang, J.-J. Zhu, Anal. Chem. 2011, 83, 661-665.

[21] H. Häkkinen, Chem. Soc. Rev. 2008, 37, 1847-1859.

[22] M. Zhu, C. M. Aikens, F. J. Hollander, G. C. Schatz, R. Jin, J. Am. Chem. Soc. 2008, 130, 5883-5885.

[23] M. Zhu, W. T. Eckenhoff, T. Pintauer, R. Jin, J. Phys. Chem. C 2008, 112, 14221-14224.

[24] C. M. Aikens, J. Phys. Chem. A 2009, 113, 10811-10817.

[25] C. M. Aikens, J. Phys. Chem. Lett. 2011, 2, 99-104.

[26] D. Jiang, Nanoscale 2013, 5, 7149-7160.

[27] R. Jin, Nanoscale 2015, 7, 1549-1565. 
[28] O. Toikkanen, V. Ruiz, G. Rönnholm, N. Kalkkinen, P. Liljeroth, B. M. Quinn, J. Am. Chem. Soc. 2008, 130, 11049-11055.

[29] H. Qian, C. Liu, R. Jin, Sci. China Chem. 2012, 55, 2359-2365.

[30] P. Maity, S. Xie, M. Yamauchi, T. Tsukuda, Nanoscale 2012, 4, 4027-4037.

[31] M. A. Tofanelli, C. J. Ackerson, J. Am. Chem. Soc. 2012, 134, 16937-16940.

[32] A. C. Reber, S. N. Khanna, Acc. Chem. Res. 2017, 50, 255-263.

[33] R. Jin, Nanoscale 2010, 2, 343-362.

[34] A. Dass, R. Guo, J. B. Tracy, R. Balasubramanian, A. D. Douglas, R. W. Murray, Langmuir 2008, 24, 310-315.

[35] R. Tsunoyama, H. Tsunoyama, P. Pannopard, J. Limtrakul, T. Tsukuda, J. Phys. Chem. C 2010, 114, 16004-16009.

[36] Z. Ma, P. Wang, L. Xiong, Y. Pei, Wiley Interdiscip. Rev. Comput. Mol. Sci. 2017, 7, e1315.

[37] D. Jiang, R. L. Whetten, W. Luo, S. Dai, J. Phys. Chem. C 2009, 113, 1729117295.

[38] E. Zeller, H. Beruda, H. Schmidbaur, Inorg. Chem. 1993, 32, 3203-3204.

[39] P. Pyykkö, N. Runeberg, J. Chem. Soc., Chem. Commun. 1993, 1812-1813.

[40] S.-S. Zhang, L. Feng, R. D. Senanayake, C. M. Aikens, X.-P. Wang, Q.-Q. Zhao, C.-H. Tung, D. Sun, Chem. Sci. 2018, DOI 10.1039/C7SC03566G.

[41] D. Jiang, S. Dai, Inorg. Chem. 2009, 48, 2720-2722.

[42] M. Walter, in High Perform. Comput. Sci. Eng. '10, Springer Berlin Heidelberg, Berlin, Heidelberg, 2011, pp. 29-41.

[43] A. W. Castleman, S. N. Khanna, J. Phys. Chem. C 2009, 113, 2664-2675.

[44] K. Freitag, H. Banh, C. Gemel, R. W. Seidel, S. Kahlal, J.-Y. Saillard, R. A. Fischer, Chem. Commun. 2014, 50, 8681-8684.

[45] F. Gam, D. Paez-Hernandez, R. Arratia-Perez, C. W. Liu, S. Kahlal, J.-Y. Saillard, A. Muñoz-Castro, Chem. - A Eur. J. 2017, 23, 11330-11337.

[46] K. G. Dyall, K. Fægri, Introduction to Relativistic Quantum Chemistry, Oxford University Press, New York, 2007.

[47] Amsterdam Density Functional (ADF 2016) Code, Vrije Universiteit: Amsterdam, The Netherlands. Available at: http://www.scm.com

[48] E. van Lenthe, E.-J. J. Baerends, J. G. Snijders, J. Chem. Phys. 1994, 101, 9783.

[49] J. P. Perdew, K. Burke, Y. Wang, Phys. Rev. B 1996, 54, 16533-16539.

[50] J. P. Perdew, K. Burke, M. Ernzerhof, Phys. Rev. Lett. 1997, 78, 1396-1396.

[51] O. Lopez-Acevedo, J. Akola, R. L. Whetten, H. Gronbeck, H. Ha kkinen, J. Phys. Chem. C 2009, 113, 5035-5038.

[52] J. Akola, M. Walter, R. L. Whetten, H. Häkkinen, H. Grönbeck, J. Am. Chem. Soc. 2008, 130, 3756-3757.

[53] D. Jiang, M. Kühn, Q. Tang, F. Weigend, J. Phys. Chem. Lett. 2014, 5, 32863289.

[54] S. Grimme, Wiley Interdiscip. Rev. Comput. Mol. Sci. 2011, 1, 211-228. 
[55] S. Grimme, J. Comput. Chem. 2006, 27, 1787-1799.

[56] L. Versluis, T. Ziegler, J. Chem. Phys. 1988, 88, 322-328.

[57] H. Jacobsen, A. Bérces, D. P. Swerhone, T. Ziegler, Comput. Phys. Commun. 1997, 100, 263-276.

[58] S. K. Wolff, Int. J. Quantum Chem. 2005, 104, 645-659.

[59] A. Klamt, G. Schüürmann, J. Chem. Soc., Perkin Trans. 2 1993, 105, 799-805.

[60] A. Klamt, V. Jonas, J. Chem. Phys. 1996, 105, 9972.

[61] C. M. Aikens, J. Phys. Chem. Lett. 2010, 1, 2594-2599.

[62] H. Yang, Y. Wang, H. Huang, L. Gell, L. Lehtovaara, S. Malola, H. Häkkinen, N. Zheng, Nat. Commun. 2013, 4, 2422.

[63] A. Muñoz-Castro, Phys. Chem. Chem. Phys. 2016, 18, 31419-31423.

[64] F. L. Hirshfeld, Theor. Chim. Acta 1977, 44, 129-138.

[65] K. B. Wiberg, P. R. Rablen, J. Comput. Chem. 1993, 14, 1504-1518.

[66] M. A. Tofanelli, K. Salorinne, T. W. Ni, S. Malola, B. Newell, B. Phillips, H. Häkkinen, C. J. Ackerson, Chem. Sci. 2016, 7, 1882-1890.

[67] M. Walter, J. Akola, O. Lopez-Acevedo, P. D. Jadzinsky, G. Calero, C. J. Ackerson, R. L. Whetten, H. Grönbeck, H. Häkkinen, Proc. Natl. Acad. Sci. U. S. A. 2008, 105, 9157-62.

[68] S. Matsuo, S. Takano, S. Yamazoe, K. Koyasu, T. Tsukuda, ChemElectroChem 2016, 3, 1206-1211.

[69] M. A. Tofanelli, T. W. Ni, B. D. Phillips, C. J. Ackerson, Inorg. Chem. 2016, 55, 999-1001.

[70] K. Kwak, Q. Tang, M. Kim, D. Jiang, D. Lee, J. Am. Chem. Soc. 2015, 137, 10833-10840.

[71] A. Muñoz-Castro, Chem. Sci. 2014, 5, 4749-4754.

[72] R. J. Gillespie, Coord. Chem. Rev. 2008, 252, 1315-1327.

[73] R. King, Coord. Chem. Rev. 2000, 197, 141-168.

[74] J. P. Foster, F. Weinhold, J. Am. Chem. Soc. 1980, 102, 7211-7218.

[75] A. Muñoz-Castro, R. B. King, Int. J. Quantum Chem. 2017, 117, e25331.

[76] W. W. Xu, B. Zhu, X. C. Zeng, Y. Gao, Nat. Commun. 2016, 7, 13574.

[77] L. Cheng, Y. Yuan, X. Zhang, J. Yang, Angew. Chemie Int. Ed. 2013, 52, 90359039.

[78] L. Liu, J. Yuan, L. Cheng, J. Yang, Nanoscale 2017, 9, 856-861.

[79] N. Takagi, K. Ishimura, M. Matsui, R. Fukuda, T. Matsui, T. Nakajima, M. Ehara, S. Sakaki, J. Am. Chem. Soc. 2015, 137, 8593-8602.

[80] Z. Tian, L. Cheng, J. Phys. Chem. C 2017, 121, 20458-20467.

[81] T. Tsukuda, H. Häkkinen, Protected Metal Clusters: From Fundamentals to Applications, Elsevier, 2015.

[82] K. L. D. M. Weerawardene, C. M. Aikens, J. Am. Chem. Soc. 2016, 138, 1120211210. 
[83] I. E. Santizo, F. Hidalgo, L. A. Pérez, C. Noguez, I. L. Garzón, J. Phys. Chem. C 2008, 112, 17533-17539.

[84] A. J. Karttunen, M. Linnolahti, T. A. Pakkanen, P. Pyykkö, Chem. Commun. 2008, 465-467.

[85] H. Häkkinen, M. Walter, H. Grönbeck, J. Phys. Chem. B 2006, 110, 9927-9931.

[86] I. Dolamic, S. Knoppe, A. Dass, T. Bürgi, Nat. Commun. 2012, 3, 798.

[87] H. Qian, W. T. Eckenhoff, Y. Zhu, T. Pintauer, R. Jin, J. Am. Chem. Soc. 2010, $132,8280-8281$.

[88] O. Lopez-Acevedo, H. Tsunoyama, T. Tsukuda, C. M. Aikens, H. Häkkinen, C. M. Aikens, J. Am. Chem. Soc. 2010, 132, 8210-8218.

[89] Z. T. Tang, Chiral Nanomaterials: Preparation, Properties and Applications, Wiley-VCH Verlag GmbH \& Co. KGaA, Weinheim, Germany, 2018.

[90] T. G. Schaaff, R. L. Whetten, J. Phys. Chem. B 2000, 104, 2630-2641.

[91] T. G. Schaaff, G. Knight, M. N. Shafigullin, R. F. Borkman, R. L. Whetten, J. Phys. Chem. B 1998, 102, 10643-10646. 
Figures Tables

Table 1. Selected averaged geometrical parameters and HOMO-LUMO gap for $\left[\mathrm{Au}_{12}(\mathrm{SMe})_{6}\right]^{2-}$ and $\left[\mathrm{Au}_{25}(\mathrm{SMe})_{18}\right]^{-}$

\begin{tabular}{|c|c|c|}
\hline & {$\left[\mathrm{Au}_{12}(\mathrm{SMe})_{6}\right]^{2-}$} & {$\left[\mathrm{Au}_{25}(\mathrm{SMe})_{18}\right]^{-}$} \\
\hline $\mathrm{Au}-\mathrm{Au}^{\mathrm{a}}$ & 2.805 & 2.861 \\
\hline $\mathrm{Au}-\mathrm{Au}^{\mathrm{b}}$ & 2.851 & 3.071 \\
\hline $\mathrm{Au}-\mathrm{S}$ & 2.479 & 2.446 \\
\hline $\begin{array}{c}\text { HOMO- } \\
\text { LUMO }\end{array}$ & 1.50 & 1.20 \\
\hline & & \\
\hline
\end{tabular}

${ }^{a}$ Distances within the core cage.

${ }^{\mathrm{b}}$ Distances between core and $\mathrm{Au}$ in the protecting layer. 
Entry for the Table of Contents (Please choose one layout)

Layout 1:

\section{ARTICLE}

$\left[\mathrm{Au}_{12}(\mathrm{SR})_{6}\right]^{2-}$, As Smaller 8-electron Gold Nanocluster Retaining an $\mathrm{SP}^{3}$ core. Evaluation of Bonding and Optical Properties from Relativistic DFT Calculations

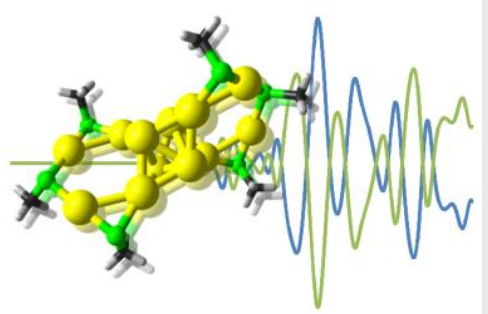

Alvaro Muñoz-Castro and Jean-Yves Saillard

Page No. - Page No.

Title 